\title{
Implementation of the South Atlantic Bight Synoptic Offshore Observational Network
}

\author{
Harcey E. Scim \\ Skidaway Institute of Oceanography - Sacannah, Georgia LSA
}

\begin{abstract}
Continuous information on coastal ocean conditions in the South Atlantic Bight (SAB), provided by an interdisciplinary real-time coastal ocean observing network, is now accessible. Many applications are envisioned. Academic researchers will use the network for targeted research and as a test bed for sensor development. The National Weather Service will use the continuously available meteorological data to predict, more accurately, weather conditions affecting the eastern seaboard of the U.S. Resource managers will be able to manage, more effectively, the use of the SAB coastal waters. The network can also serve as the nucleus of an observing system that will provide in situ observations for a nowcast/forecast regional coupled ocean/atmosphere model of the SAB.
\end{abstract}

\section{Introduction}

Since the 1980s the U.S. Navy has operated aircrew training facilities similar to those popularized in the movie Top Gunt. One of these Tactical Aircrew Combat Training Systems (TACTS) is located in the coastal waters off of Georgia, covering a $115 \mathrm{~km} \times 50 \mathrm{~km}$ area of the middle to outer continental shelf (Figure 1), roughly $6000 \mathrm{~km}^{2}$. It consists of a grid of eight platforms that are similar to small oil rigs. There are two styles of platforms, four-legged master platforms and three-legged remotes (Figure 2). This unmanned facility exists to provide rapid (realtime) tracking of military combat aircraft (typically F-18s) on the flight range, and permits instructors onshore to observe and interact with

It becane apparent that a
partnership with TACTS
could provide the
oceanographic community
with a unique resource for
studying the coastal ocean.

manager of the Gray's Reef National Marine Sanctuary (GRNMS) made initial contacts with TACTS operators in the mid 1990s. The manager of the GRNMS, which is located $10 \mathrm{~km}$ inshore of the shoreward-most platforms (Figure 1), was interested in using the structures to mount a radar unit for monitoring ship traffic in the Sanctuary. Soon afterward the National Oceanographic Partnership Program (NOPP) legislation was enacted and a call for proposals to develop ocean observing systems was announced.

Prompted by the GRNMS managrer and the NOPP announcement, scientists from the Skidaway Institute of Oceanography (SkIO) made contact with TACTS. We were surprised and delighted in our initial meeting with the TACTS range managers to learn that they were not only willing to have us place instruments on the towers, but that they could also provide power, considerable communications bandwidth (by oceanographic standards), and monthly maintenance support in the form of helicopter transportation to the towers. It became apparent that a partnership with TACTS could provide the oceanographic community with a unique resource for studying the coastal ocean.

The TACTS towers may fulfill a number of needs recently identified in planning for the development of a U.S. coastal global ocean observing system (C-GOOS). Among the suggestions made by the C-GOOS steering committee (Malone et al., 1999) are the establishment of pilot regional observation systems, the development of testbed sites for the measurement of in situ chemical and biological properties, and strong feedback between monitoring, research and modeling. Our efforts are consistent with these goals.

This article describes progress in developing a regional ocean observing system. The partners involved are presented first, followed by the development plan. 


\section{TABLE 1.}

Skidaway Institute of Oceanography (SkI0)

TACTS, NWAS

University of North Carolina

University of Georgia \& Environmental

Protection Agency

South Carolina Department of Natural Resources

Gray's Reef National Marine Sanctuary, NOAA
Jack Blanton

Rick Jahnke

Jim Nelson

Gus Paffenhöfer

Harvey Seim

Richard Bolin

John Bane

Francisco Werner

Mary Ann Moran

Richard Zepp

Charlie Barans
Program management, systems design and deployment, cross-shelf exchange, internal waves, bio-optics, zooplankton ecology, geochemistry

Helicopter support

Data assimilative circulation modeling, air-sea interactions

Colored Dissolved Organic Matter (CDOM)

Fisheries management Diving support, fisheries studies
Our current system, which includes a fully instrumented platform, real-time communication and data archiving and distribution, is also described. Our short-term development plans and conclusions about the program are given last.

\section{The Partnership}

Coastal oceanography is an interdisciplinary science. To ensure that a range of interests were included, a partnership was formed by the researchers listed in Table 1 representing academic, state and federal governmental agencies, as required by NOPP.

This group of investigators developed a plan to instrument the TACTS platforms, christened the South Atlantic Bight Synoptic Offshore Observational Network (SABSOON). The plan involves the design and deployment of communications, power, data acquisition, and sensor carriage systems at as many of the eight offshore platforms as possible, and the development of an onshore data management and distribution system. The instrumentation to be deployed is, for the most part, standard equipment with the goal of first establishing an observational baseline that can be built upon with time.

The use of offshore platforms for scientific studies was the subject of a special issue of the Marine Technology Society Journal in 1993 (Vol. 27, no 2). A series of articles summarized applications of instrumented platforms in climate, meteorological and oceanographic research, and discussed the challenges posed by the use of such platforms for scientific purposes. Due to the high capital costs for offshore fixed platforms, instrumented structures have typically been constructed for purposes other than oceanographic research, notably as offshore oil platforms and navigational structures. In the case of operating oil platforms, activities on the structures can impose constraints on scientific data collection (e.g. Cooper et al., 1993).

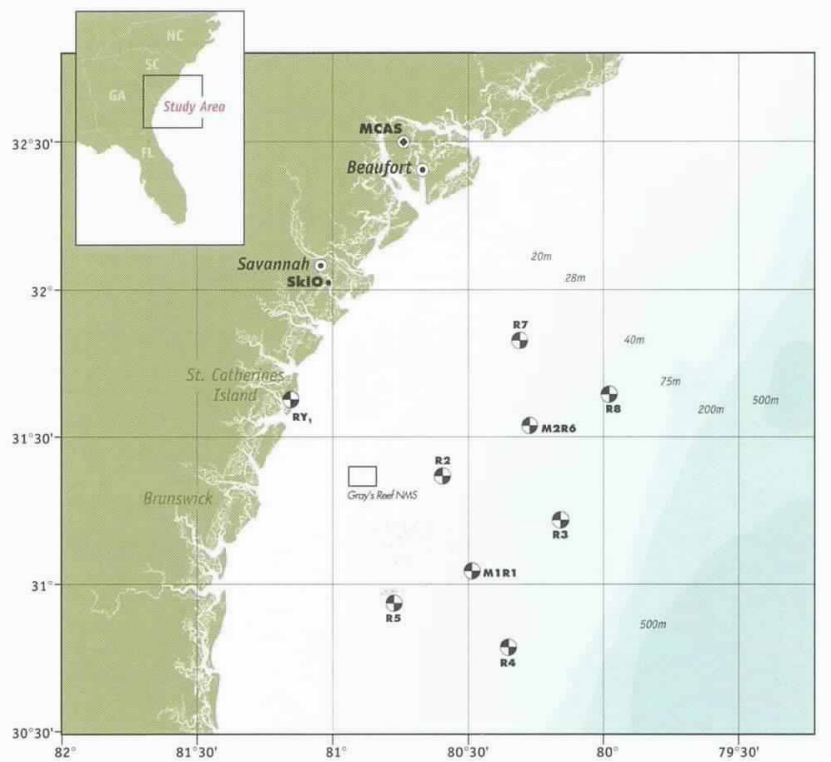

Figure 1: Map of the continental shelf off of Georoia showing the position of the Navy towers.

The TACTS towers offer a number of unique advantages compared to many other offshore platforms. The platforms are distributed in a regularly spaced array on the broadest section of continental shelf along the U.S. eastern seaboard, a position that is very well situated for study of mesoscale processes on the mid-to-outer shelf. Unlike working oil platforms, the TACTS towers have limited superstructure and should not suffer from flow distortion to the extent discussed by Cooper et al. (1993). Since TACTS activities on the towers themselves focus primarily on maintenance of the platforms and associated power and communications systems, these cause minimal interference with scientific data collection. In fact, such infrastructure maintenance is of direct benefit 
to the SABSOON program. Three other TACTS facilities that are on or in coastal waters are located near Norfolk, VA, Cherry Point, NC and Key West, FL and may also be suitable for hosting regional observing systems.

\section{The Development Plan}

Although the TACTS towers existed and the communications system was operational at the start of SABSOON, instrumenting the towers for scientific research required a substantial design effort. To proceed in a systematic manner a three-phase program was defined. Phase 1 is complete and Phase 2 is underway. In Phase 1 , science power and communications were interfaced with TACTS existing equipment. The meteorological system and ocean sensors deployment system, and a computer acquisition system for the tower were designed. A data archiving and distribution system was developed. It was decided that prototypes for these systems should be deployed at a single master tower and tested for at least several months.

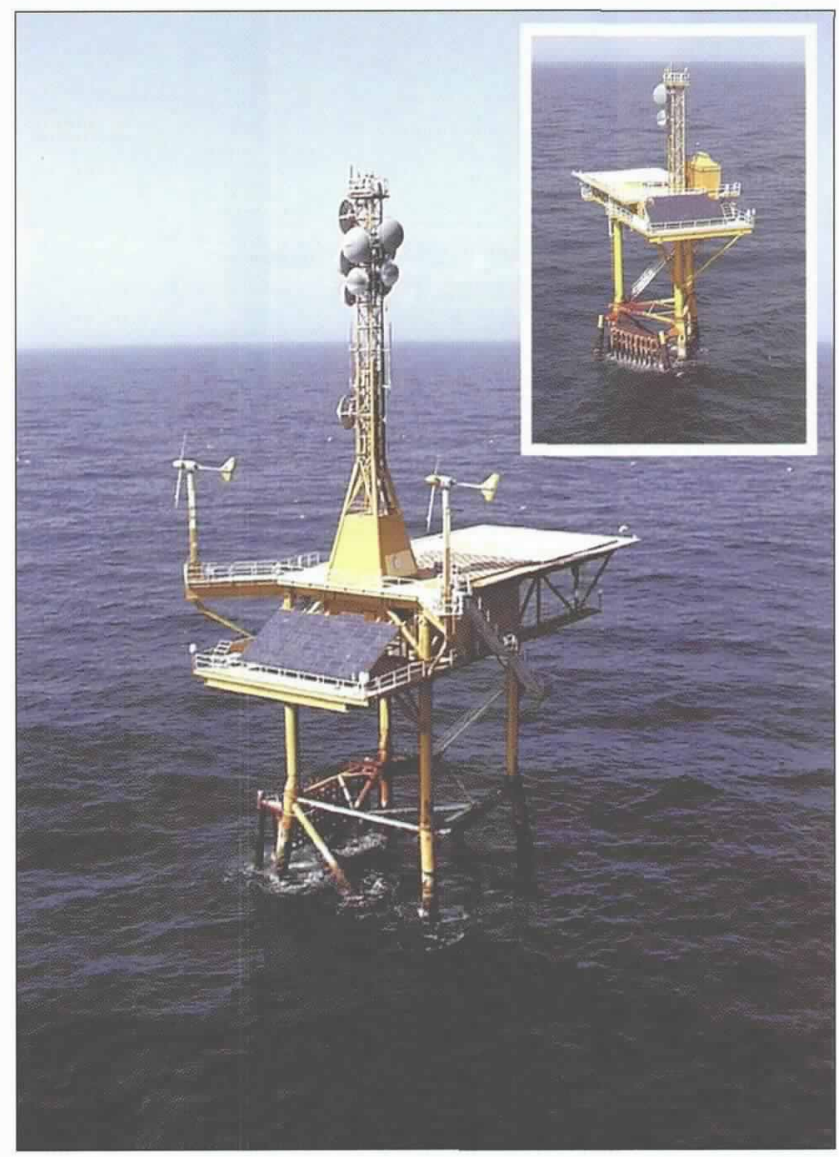

Figure 2: Pictures of the four-legged master towers and the three-legged remote towers.

In Phase 2, SABSOON will instrument two additional towers, extending the system to the remote platforms (the second type of tower in the system). Unlike the master platforms, which have solar panels, wind generators, a diesel generator and a large environmen- tally-controlled enclosure, the remote platforms have limited power, a small waterproof enclosure that is not dehumidified or air-conditioned, and very little available communications (Figure 2). Phase 2 therefore will include design and deployment of a supplemental power system and a separate communication system to serve SABSOON's needs.

In Phase 3, a number of other platforms are to be instrumented. This will include the last master tower, where a last design challenge exists, that of powering a profiling in-water system. Somewhere between one and four additional remote towers will be enabled in Phase 3. The total number of towers that can be instrumented with the initial NOPP funding is uncertain, due to unanticipated costs associated with power and communications upgrades at the remotes.

\section{Current Status of SABSOON}

Phase 1

In Phase 1 of the project, instrument systems were designed and tested during the initial deployment at tower R2 (Figure 1). The completion of Phase 1 is largely the accomplishment of Travis McKissack, the chief engineer on the project, and the engineering staff at SkIO. Platform R2, the central master platform in the TACTS system, is now fully instrumented with core packages of meteorological and oceanographic instruments. An underwater video system was also developed.

The Navy's microwave system has permitted us to establish a high bandwidth, two-way communications system. The current bandwidth is $1.5 \mathrm{MHz}$ (equivalent to a T1 line) and internet communication protocols are used for transmission. Intelligent devices on the tower are assigned IP numbers and form an extension of the SkIO local area network (LAN). To ensure uninterrupted acquisition of data, low power computers are installed on the R2 platform to log observations locally. These computers are connected to the Skidaway Institute LAN through the microwave/dedicated phone line system. All raw data files are copied hourly to shore, ensuring no data loss, even if the communication system goes down for an extended period of time (current maximum of 7 days). Automated processing of the raw files occurs periodically (hourly at present) and performs error checking, calculates derived quantities, and appends the observations to a database of processed observations.

The data acquisition system (DAS) for the tower instruments was designed to accept input from a variety of oceanographic and meteorological sensors. The basic DAS package is a modular design based on PC104 architecture. The PC-104 system was selected for its small form factor, low power consumption, extensible design, and flexibility in configuration. Stacked input/output cards are matched to the particular instrument application (e.g. DC voltage, RS-232 output) and can be easily rearranged if the requirements for a particular instrument package change. 


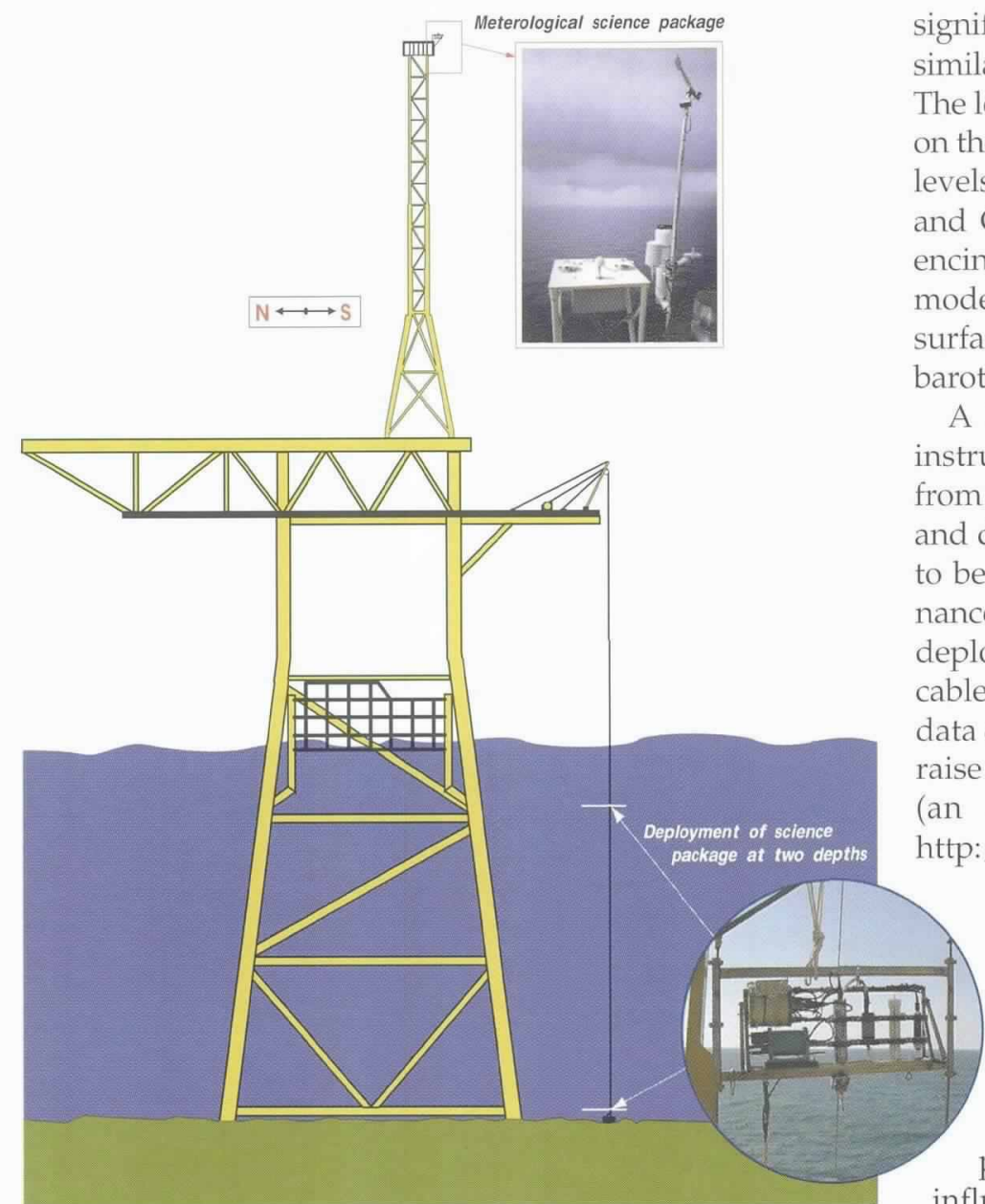

Figure 3: Schematic drawing of the tower, the meteorological package and inwater deployment system.

A complete meteorological sensor suite, modeled after the IMET (Improved Meteorology) system used on moorings (Hosom et al., 1995) is installed at the top of the R2 antenna truss (Figure 3). This measures wind speed and direction, barometric pressure, air temperature, relative humidity, precipitation, long- and shortwave solar irradiance, and photosynthetically available radiation (PAR). These sensors constitute a suite of measurements suitable for assessing the flux of heat and momentum between the ocean and atmosphere. In mid-November a second meteorological package (anemometer, barometric pressure, air temperature and relative humidity) was installed at $10 \mathrm{~m}$ height on the northern side of the platform. The ten meter installation is a standard height of observations in meteorology, and the observations will be used to evaluate how the height of the instruments on the antenna truss $(50 \mathrm{~m})$ affects the measurements under varied conditions in the marine boundary layer.

A high resolution pressure sensor is rigidly attached to the platform (at $6 \mathrm{~m}$ depth) to measure water level and surface gravity waves (sampling at $2 \mathrm{~Hz}$ ). The high frequency signal from the pressure sensor is used to estimate significant wave height and peak period using algorithms similar to those used by the National Weather Service. The low-passed signal from the sensor measures the tides on the shelf as well as lower frequency variations in water levels associated with storms, coastally trapped waves, and Gulf Stream meanders. Future plans include referencing water level measurements to the GPS geoid model. If successful, cross-shelf estimates of absolute sea surface slopes will provide a measure of total alongshelf barotropic transport on the continental shelf.

A key requirement for the design of the in-water instrument deployment system is to permit servicing from the tower. This eliminates the need for regular ship and diver support at the platforms, and allows servicing to be coordinated with the regularly scheduled maintenance flights of the TACTS helicopter. The instrument deployment system (Figure 3) consists of dual guide cables and anchor weight, a pair of instrument packages, data cable, hoist cable, and a winch. A single operator can raise and secure the instrument packages for servicing (an animated CAD sequence can be viewed at http:/ /www.skio.peachnet.edu/projects/sabsoon.html).

Both near-surface and near-bottom instrument packages have a conductivity/temperature/pressure sensor, used to measure temperature, salinity and density, and dissolved organic matter (DOM) and chlorophyll- $a$ fluorometers. The salinity and temperature measurements provide a measure of vertical stratification on the shelf, and provide a measure of Gulf Stream or coastal water influences in the SABSOON area. Coastal waters are an important source of DOM, and its presence is an indicator of cross-shelf exchange of terrestrially-derived material. The chlorophyll- $a$ fluorescence is a proxy measure of the concentration of phytoplankton in the water. Light levels near the sea floor are monitored on the near-bottom package with an underwater PAR sensor.

In addition to the equipment installed on the tower, an artificial reef and underwater video system has been deployed to monitor fish abundance and behavior. A set of artificial reef structures is deployed in a circle, with a six-camera system pointing outward from a central position. Cabling runs from the camera system, through a pull tube on the tower leg, and upward into the tower instrument room. This project component is evaluating underwater video observations as a fisheries management tool, initially targeting study of the aggregation behavior of gag grouper prior to spawning.

The most recent observations are posted on the project web site (www.skio.peachnet.edu/projects/sabsoon.html). Observations are presented in tables, and graphs of the last 24 hours, 7 days, and 30 days are available for most of the data streams. The web site is, of course, a work in progress. At present, it includes pages on the partners, scientific objectives of the project, the existing Navy system, the SABSOON components, the real-time observations, and data-sharing policies. The towers have also been designated as C-MAN 

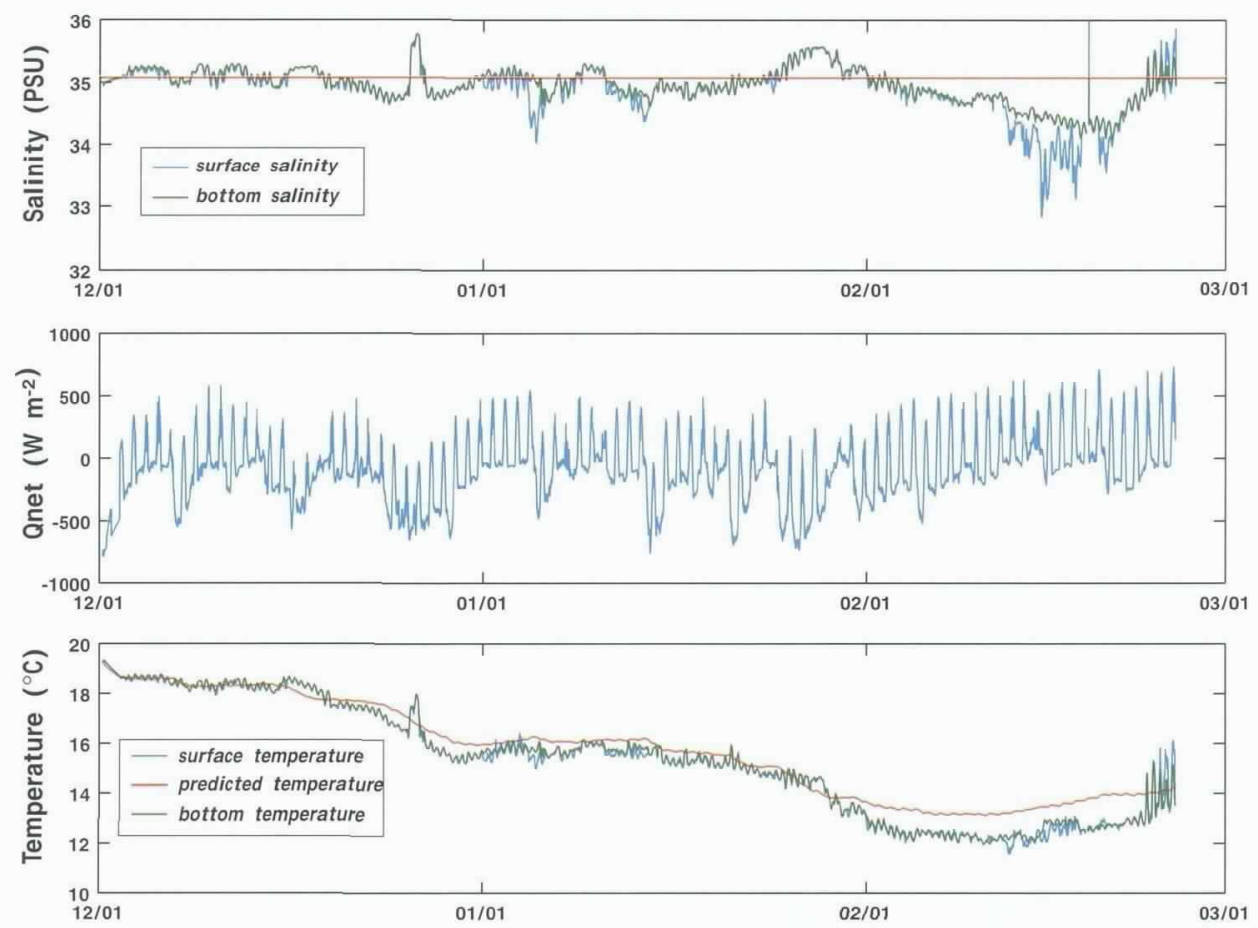

Figure 4: Time series of a) top and bottom salinity; b) net heat flux from meteorological observations; and c) top and bottom measured and predicted temperature at tower $R 2$.

(coastal marine automated network) stations with the National Data Buoy Center. Each hour data are extracted from the database and formatted to meet standards for ingestion into the World Meteorological Organization's Global Telecommunications System.

The existing instrumentation is already providing insights into processes operative on the shelf. Top and bottom salinity records from R2 (Figure 4a) exhibit considerable variability in mid-shelf salinity and salinity stratification. Several significant departures from an average of 35.1 psu are apparent since December 1, 1999. Near the end of December, salinities approached 36 psu during a brief excursion of Gulf Stream water onto the shelf. Several instances of vertical stratification in early January and a sustained period in midFebruary are associated with crossshelf movement of low-salinity estuarine waters. The meteorological observations can be used to estimate the net heat flux out of the ocean (e.g. Austin and Lentz, 1999) and are shown in Figure 4b. Assuming that waters are mixed top to bottom, the heat flux is integrated in time to estimate the ocean temperature (Figure 4c). The predicted temperature is a reasonable approximation of the measured temperatures when the salinity is near its average value, but is systematically lower when salinities are below average. Salinity and temperature increase moving offshore in recent shipboard surveys. This cross-shelf structure and the time series from $\mathrm{R} 2$ suggest that low salinity/low tem- perature water moves $10-20 \mathrm{~km}$ cross-shelf over week or longer time scales. The mechanisms responsible for this cross-shelf motion are being investigated, but there is not an obvious correlation of these events with the wind field.

\section{Phase 2}

The extension of the network to several other platforms, is now underway. After establishing power and communications for science needs, we deployed an upward-looking acoustic doppler current profiler (ADCP) at a second master platform (M2) in mid-April, 2000. This instrument measures ocean currents in $1 \mathrm{~m}$ vertical bins from near the ocean surface to near the ocean floor, providing a measure of water motions on the shelf. Phase 2 also requires some new design work, principally establishing power and communications at the remote platforms. The remote towers currently do not have any available bandwidth on their existing communications link to the master platforms. The first remote tower to receive power and communications will be on the northeastern corner of the array (R8). Once linked into the network, we will deploy a meteorological sensor suite and tide and surface wave sensor. From an engineering viewpoint this will complete the design and testing of all the major components necessary to fully instrument the tower array. From a scientific viewpoint, instrumenting $\mathrm{R} 8$ will provide information on cross-shelf structure. Because of its prox- 
imity to the Gulf Stream, we anticipate significantly different atmospheric and oceanographic conditions at R8.

During Phase 3, between one and four additional towers will be instrumented, depending on available funding. We also will deploy controllable water samplers to collect water for chemical and biological analysis. These laboratory-analyzed samples will provide standards for in situ chemical and biological sensors that may be deployed.

As the observational network expands during Phases 2 and 3, a modeling effort that includes data assimilation can begin. The model being used is QUODDY, a finite-element circulation model that has been used extensively in the GLOBEC studies of Georges Bank (Lynch et al., 1996). Data from the towers and atmospheric forecasts from the National Weather Service in Jacksonville, FL will be used in forcing an ocean hindcast and forecast. Hydrographic information to initialize the model will come from aircraft surveys using expendable profilers and from shipboard surveys using an undulating towed body. The long-term objective is to develop an operational forecast model of the South Atlantic Bight shelf in the vicinity of SABSOON. A proposal to pursue this, in concert with a mesoscale atmospheric model of northern Florida and the southern $S A B$, is pending.

\section{Conclusions}

Implementation of SABSOON is well under way. The prototype system was first operational in June 1999, has been fully operational since October, 1999, and is functioning well. As the months pass we are gaining confidence in our design work and learning important lessons about the maintenance required to keep the system performing well. An excellent working relationship within our partnership has developed and we are in a strong position to move forward with the rest of the project.

Without the incentive provided by NOPP, it is unlikely we would have initiated contact with TACTS. An alliance between academic researchers and a branch of the operational Nary may not be unique, but it is certainly new to most of us involved in SABSOON. The TACTS group commitment to helping make the project move forward has been impressive. SABSOON certainly could not have happened without them.

Instrumenting the Navy platforms for real-time observations of the coastal ocean is viable. The initial deployments have been of fairly common equipment, but one of the most promising aspects of SABSOON is its potential to serve as a test bed for new and innovative instruments. The combination of offshore location, ease of servicing and high bandwidth communications in a mesoscale grid make the network unique.

Continued development and maintenance of SABSOON is uncertain. Initial funding by NOPP provides support until July, 2000. Though SABSOON has pro- gressed well, several additional years will be required to finish instrumenting all eight towers. No funds are available to continue SABSOON from NOPP at this time. Extensive ocean observing systems are difficult to build and maintain and are feasible only if sustained funding is available. If NOPP chooses to foster efforts to observe and model regions of the coastal ocean, a commitment to provide sustained funding over 5 to 10 year periods needs to be considered.

Full implementation of SABSOON will provide the scientific community, resource managers, and educators with real-time access to the coastal ocean. This will enhance our understanding of the physics of the coastal zone and its ecosystem, provide a monitoring system for coastal resources and coastal hazards, and an interactive observational system that can be used by educators to study coastal issues.

\section{Acknowledgements}

Funding for SABSOON has come from the National Oceanographic Partnership Program and is gratefully acknowledged. Mechanical engineering (and AutoCAD drawings) by Jimmy Williams and circuit design work by Caroll Baker have made the project possible. We also thank Jud Gatch at TACTS and Carl Drawdy with PRC/Litton for their advice and support. Technicians Trent Moore and Cheryl Burden are making sure the datastream is continuous and of high quality, computer specialist Sara Haines designed the real-time website data display, and the assistance of the Skidaway boat and shop crew on numerous occasions is appreciated and gratefully acknowledged.

\section{REFERENCES}

Austin, J.A. and S.J. Lentz, 1999: The relationship between synoptic weather systems and meteorological forcing on the North Carolina inner shelf. I. Geoplyys. Res., 104, 18,159-18,185.

Cooper, C., G. Forristall, R. Hamilton and C. Ebbesmeyer, 1993: Utilization of offshore oil platforms for meteorological and oceanographic measurements. MTS Jour., 27, 10-23.

Hosom, D.S., R.A. Weller, R.E. Payne and K.E. Prada, 1995: The IMET (Improved Meteorology) ship and buoy systems. J. Atmos. Ocean. Tech, 12, 3, 527-540.

Lynch, D.R., J.T.C. Ip, C.E. Naimie and F.E. Werner, 1996: Comprehensive coastal circulation model with application to the Gulf of Maine. Cont. Shelf Res., 16, 875-906.

Malone, T, N. Andersen, P. Brewer, E. Buckley, H. Frey, F. Grassle, G. Gross, K. Tenore,. L. Walstad, C. Woody and J. Yoder, 1999: Challenges and promise of designing and implementing an ocean observing system for U.S. coastal waters. U.S. Coastal-global Ocean Obsering System Report. LMCES Contribution No. 3217, 49 pp. 